\title{
THE EFFECT OF SHORT-TERM STARVATION ON SOME PHYSIOLOGICAL AND MORPHOLOGICAL PARAMETERS IN JUVENILE SIBERIAN STURGEON, ACIPENSER BAERII (ACTINOPTERYGII: ACIPENSERIFORMES: ACIPENSERIDAE)
}

\author{
Ghasem ASHOURI ${ }^{1 *}$, Vahid YAVARI ${ }^{2}$, Mahmood BAHMANI ${ }^{3}$, Mohammad A. YAZDANI ${ }^{3}$, \\ Rezvan KAZEMI $^{3}$, Vahid MORSHEDI ${ }^{4}$, and Mehrdad FATOLLAHI ${ }^{1}$ \\ ${ }^{1}$ Department of Fisheries, Faculty of Natural Resources, University of Shahr-e-kord, Shahr-e-kord, Iran \\ ${ }^{2}$ Department of Fisheries, Faculty of Marine Natural Resources, \\ Khoramshahr Marine Science and Technology University, Khoramshahr, Iran \\ ${ }^{3}$ International Sturgeon Research Institute of Rasht, Guilan, Iran \\ ${ }^{4}$ Persian Gulf Research and Study Centre, Persian Gulf University of Bushehr, Bushehr, Iran
}

Ashouri Gh., Yavari V., Bahmani M., Yazdani M.A., Kazemi R., Morshedi V., Fatollahi M.. 2013. The effect of short-term starvation on some physiological and morphological parameters in juvenile Siberian sturgeon, Acipenser baerii (Actinopterygii: Acipenseriformes: Acipenseridae). Acta Ichthyol. Piscat. 43 (2): 145-150.

\begin{abstract}
Background. Fish may experience periods of food deprivation or starvation in nature and under culture conditions. Because of the wild stock reduction of some sturgeon species, Siberian sturgeon, Acipenser baerii Brandt, 1869, has been used as a biological model of physiological and nutritional studies since the 1980s. There are no published records on the physiological responses of Siberian sturgeon to starvation. Hence, in this study the effect of shortterm starvation $\left(0,2,4\right.$, and 8 days) on plasma thyroid hormones $\left(\mathrm{T}_{3}\right.$ and $\left.\mathrm{T}_{4}\right)$, total protein levels, and hepatosomatic- (HSI), viscero-somatic- (VSI), and digestive-somatic (DSI) indices in juvenile Siberian sturgeon was investigated.

Materials and methods. The experiment was conducted at the International Sturgeon Research Institute of Rasht (Iran) in October 2009, using a semi-natural environment (natural photoperiod and natural water temperature fluctuations). After a period of adaptation (10 days on a formulated diet), 180 juvenile Siberian sturgeon individuals (mean weight \pm standard error at start of experiment: $19.32 \pm 0.43, n=15$ ) were randomly distributed among twelve circular, 500-L, fibreglass tanks with a flow-through system. In this trial, control (C) was fed a formulated diet to apparent satiation four times daily throughout the experiment. The other three groups were deprived of feed for 2- (2S), 4- (4S), and 8 (8S) days, respectively. At the end of the starvation periods, blood samples were collected to analyze biochemical and physiological parameters.

Results. Plasma $T_{3}, T_{4}$, and total protein levels did not significantly vary between the fed and the starved fish. In comparison to the starved groups, after 8 days of starvation, plasma total protein in group $8 \mathrm{~S}(3.43 \pm 0.20)$ was markedly higher than in $2 \mathrm{~S}(2.67 \pm 0.07)$ and $4 \mathrm{~S}(2.37 \pm 0.12)$ groups. In the presently reported study, a decrease in the measured morphometric indices was observed with an increase in the length of the starvation period.

Conclusion. The results suggest that Siberian sturgeon has metabolic adjustment ability to short periods of starvation due to reduced basal metabolism rate and energy reserves utilization during starvation.
\end{abstract}

Keywords: food deprivation, hepato-somatic index, starvation, thyroid hormone, total protein

\section{INTRODUCTION}

Metabolic adjustments during starvation periods differ from species to species. Intraspecific adjustments to conditions occurring during such periods also depend on various factors, such as fish age, reserves availability, past nutritional history, etc. (Pérez-Jiménez et al. 2007). Several hormones play a central role in regulating energy reserves utilization during periods of food deprivation in all verte- brates, including fish (De Pedro et al. 2003). In starvation periods, basal metabolism decrease, causing the lower metabolic activity (Hornick et al. 2000). Starvation results in metabolic and endocrine alterations; for instance, basal metabolism is reduced, whose main reason is reduction in the plasma levels of anabolic hormones and increased levels of catabolic hormones (Hornick et al. 2000). Thyroid hormones, tri-iodothyronin $\left(T_{3}\right)$ and thyroxine $\left(T_{4}\right)$ play

\footnotetext{
${ }^{*}$ Correspondence: Mr Ghasem Ashouri, Department of Fisheries, Faculty of Natural Resources, P.O. Box: 88186-34141, University of Shahr-e-kord, Iran, Tel: +98 381 4424423, Fax: +98 381 4424423; Email: ghasem.ashouri@yahoo.com.
} 
a crucial role in vertebrates, affecting a variety of processes, such as metabolism, growth, differentiation and reproduction. Thyroid hormones (TH) are established to contribute in the adaptive metabolic response to starvation, and these hormones (TH) can intensify both hyperglycemic and glycogenolytic actions (De Pedro et al. 2003). Bentley (1998) has reported that starvation or reduced feeding can cause a down-regulation of the hypothalamus-pituitary gland-thyroid tissue axis, and consequently the anabolic activity is inhibited during periods of starvation. Such alterations lead to a general reduction in plasma TH levels. The precise role of TH during starvation has been little understood in ectothermic animals (De Pedro et al. 2003). Seemingly, TH regulates fish intermediary metabolism in a way similar to that in other vertebrates (Navarro and Gutiérrez 1995).

When animals encounter food limitation, they have to rely on their body reserves to provide energy for body functions (Fuglei et al. 2000). Both behavioural and physiological strategies are used to compensate for the energy shortages of the fish during starvation periods (Pottinger et al. 2003). The mobilization of stored energy under such conditions is managed by the endocrine system. Chiefly, protein reserves are preserved at the beginning of starvation, thus proteolysis occurs only when more readily available energy reserves, including liver glycogen and lipid stores have widely been consumed (Navarro and Gutiérrez 1995). Obviously, starvation will lead to morphological alterations in fish. Therefore, in order to determine dynamic (reserve) tissues supplying energy in the starvation periods, some morphological indices such as hepato-somatic index (HIS), viscero-somatic index (VSI), and digestive-somatic index (DSI) are commonly estimated. The loss of hepatic energy reserves during starvation is reflected in changes in liver weight, and therefore HSI is a useful indicator of depletion of these reserves (Leatherland and Farbridge 1992, Leiner et al. 2000). Ince and Thorpe (1976) stated that since fat is stored in fish mostly in visceral organs, during starvation this reserved fat is mobilized and causes depletion of intestinal fat and a decrease in weight. Sturgeon rearing is increasing all over the world. Because of the stock reduction of some sturgeon species, Siberian sturgeon, Acipenser baerii Brandt, 1869, has been used as a biological model for physiological and nutritional experiments since the 1980s (Fontagné et al. 2006). No study has been conducted to investigate the physiological responses of Siberian sturgeon to starvation. Hence, the presently reported research was aimed at assessing the biochemical and physiological variation in Siberian sturgeon subjected to different starvation periods. In our study, plasma levels of $\mathrm{TH}\left(\mathrm{T}_{3}\right.$ and $\left.\mathrm{T}_{4}\right)$ were measured to specify homeostatic response mechanism to starvation in this fish species.

\section{MATERIAL AND METHODS}

Animals and experimental conditions. The experiment was conducted at the International Sturgeon Research Institute of Rasht (Iran) in October 2009, using a semi- natural environment, two aspects of which were a natural photoperiod and natural water temperature fluctuations. Siberian sturgeon juveniles were obtained from a fish farm Shahid Beheshti Rasht (Iran) and transported to an indoor system at the Institute. Prior to the beginning of the trail, the fish were acclimatized to experimental conditions for a 10-day period. Pelleted feed ( $2 \mathrm{~mm}$ in diameter) was manufactured for Siberian sturgeon by the Institute Feed Laboratory, Rasht (Iran). The feed was composed of approximately $45 \%$ crude protein, $18 \%$ crude fat, $10 \%$ ash, and $8 \%$ water, $17.83 \%$ carbohydrate, and $1.17 \%$ fibre. During acclimation, fish were fed to apparent satiation four times a day. A total of 180 Siberian sturgeon juvenile individuals (mean weight \pm standard deviation at start of experiment: $19.32 \pm 0.43, n=15$ ) were then randomly distributed in twelve circular fibreglass tanks of 500-L capacity. The tanks' water was continuously replenished throughout the experiment using Sefid Rood River after filtration at a flow rate of approximately $5 \mathrm{~L} \cdot \mathrm{min}^{-1}$. The water in each tank was permanently saturated (up 92\%) with oxygen by supplying air continuously through an air-stone from an air-blower. Water quality parameters were monitored daily to ensure the fish welfare. Water temperature $\left(17.2 \pm 1.5^{\circ} \mathrm{C}\right), \mathrm{pH}$ $(7.2 \pm 0.2)$, and ammonia (lower than $\left.0.1 \mathrm{mg} \cdot \mathrm{L}^{-1}\right)$ were recorded during the experiment. In this trial, control (C) was fed a formulated diet to apparent satiation four times a day throughout the study. The other three groups were deprived of feed for 2- (2S), 4- (4S), and 8 (8S) days, respectively.

Sample collection. Three fish individuals per tank (nine per treatment) were randomly sampled at the end of the starvation periods, at day 2, 4, and 8 of the experiment. During the experiment, sampling was carried out after each starvation simultaneously with the control group. Blood samples were rapidly collected from the caudal vein using heparinized syringes. Plasma was immediately detached after centrifuging blood samples in $3000 \mathrm{rpm}$ for 10 min (Cataldi et al. 1998) and then stored at $-20^{\circ} \mathrm{C}$ (Bayunova et al. 2002) until thyroid hormones and total protein analyses were performed. Then six fish individuals per treatment were rapidly euthanized, after which whole fish body-, liver, viscera-, and digestive tract weights were recorded for the determination of HSI, VSI, and DSI.

Thyroid hormones radioimmunoassay. Plasma TH levels were measured using established double antibody $\mathrm{T}_{4}$ and $\mathrm{T}_{3}$ RIAs (Leiner et al. 2000).

Measurement of plasma total protein levels. Commercial kit (Pars Azmun, Karaj, Iran; www.parsazmun.com) was used for plasma total protein measurement. Total protein was assayed by the biuret method (kit 1500028) in the plasma.

Morphometric measurements. All morphometric indices were calculated as follows:

$$
\begin{array}{ll}
\mathrm{HIS}=100 W_{1} \cdot & W_{\mathrm{t}}^{-1} \\
\mathrm{VSI}=100 W_{\mathrm{v}} \cdot & W_{\mathrm{t}}^{-1} \\
\mathrm{DSI}=100 W_{\mathrm{d}} \cdot & W_{\mathrm{t}}^{-1}
\end{array}
$$


where: HIS = hepato-somatic index, VSI = viscero-somatic index, DSI = digestive-somatic index, $W_{1}=$ liver weight, $W_{\mathrm{t}}=$ total body weight, $W_{\mathrm{v}}=$ weight of viscera, $W_{\mathrm{d}}=$ weight of digestive tract.

Statistical analyses. Results are presented as mean \pm standard error (SD). All data comparing control and starved groups were analysed by independent $t$-test, while the starved groups' data were analyzed by one-way ANOVA using the SPSS version 17.0 for Windows software package. Significant differences among means $(P<0.05)$ were determined by the Duncan's multiple range test (Duncan 1955).

Ethical issues. This work was carried out at the rearing facility at International Sturgeon Research Institute, Rasht, Iran and under the supervision and technical support by the Institute. All the experimental procedures including euthanasia were based on the guidelines provided by the Institute. Care was taken to use only the minimum possible number of specimens for analytical work and fish were euthanized with an overdose of anaesthetic.

\section{RESULTS}

Thyroid hormones. The plasma thyroid hormones levels are presented in Fig. 1. In spite of the decrease in circulating TH (both $\mathrm{T}_{3}$ and $\mathrm{T}_{4}$ ) levels in the starved juvenile Siberian sturgeon, there were no significant differences found between the control and the starved groups $(P>0.05)$.

Total protein. Results for plasma total protein levels are showed in Fig. 2. There were no significant differences between the control and the starved groups $(P>0.05)$, but when the starved groups $(2,4$, and 8 days) were compared, the level of plasma total protein was significantly higher in the $8 \mathrm{~S}(3.43 \pm 0.20)$ group than in the $2 \mathrm{~S}(2.67$ $\pm 0.07)$ and $4 \mathrm{~S}(2.37 \pm 0.12)$ groups $(P<0.05)$.

Morphometric indices. The results for morphometric measurements are illustrated in Table 1. In this study, with an increase in the length of the starvation period, decreased values were obvious in HIS, VSI, and DSI indices

\section{- Control $\square$ Starvation}

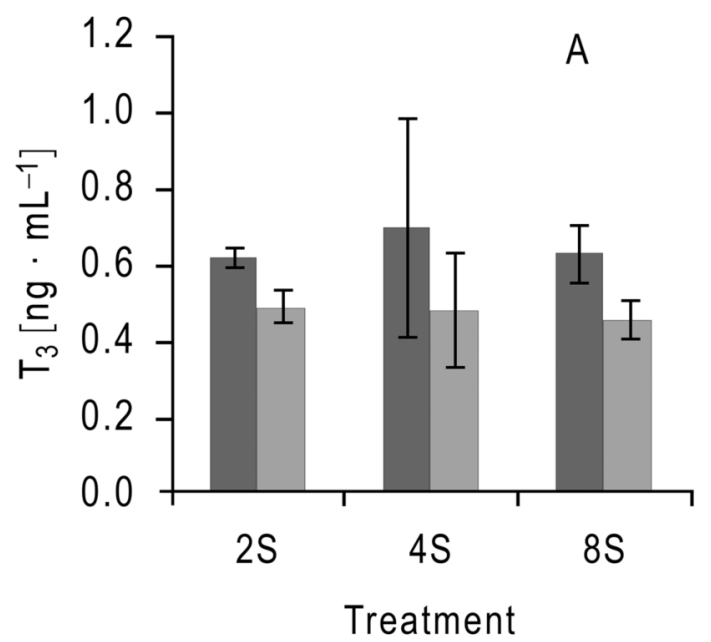

$(P<0.05)$. Only a decrease in group $2 \mathrm{~S}$ in DSI was statistically significant $(P<0.05)$, even though significant $(P<0.05)$ reductions in the three indices (HSI, VSI, and DSI) were observed in the starved juvenile Siberian sturgeon after 4 and 8 days starvation (4S and $8 \mathrm{~S}$ ).

\section{DISCUSSION}

Thyroid hormones are thought to play a role in energy conserving processes and maintaining homeostasis in a starving organism (Fuglei et al. 2000).

In the presently reported study, in spite of a slight decrease in circulating TH (both $\mathrm{T}_{3}$ and $\mathrm{T}_{4}$ ) levels in the starved juvenile Siberian sturgeon, there were no significant differences between the treatments. Yet, decreased thyroid activity in response to starvation (McBride 1967, Honma and Matsui 1973) in fish can be a homeostatic protective mechanism to prolong survival of the organism under these conditions.

The plasma levels $T_{3}$ is generally assumed to decrease during food deprivation (MacKenzie et al. 1998). During starvation, low levels of plasma $\mathrm{T}_{3}$ could be due to a reduction in monodeiodination in peripheral conversion of $T_{4}$ to $T_{3}$ and its release to the plasma (Navarro and Gutiérrez 1995). Lower concentrations of $T_{3}$ and $T_{4}$ during starvation allow the organism to conserve energy by decreasing basal metabolism rate (Hornick et al. 2000). Several studies have reported that starvation or reduced feeding can cause a down-regulation of the hypothalamushypophysis-thyroid tissue axis in fishes (Bentley 1998, Power et al. 2000). In the presently reported study, the insignificant depletion observed in plasma $T_{4}$ levels with extending the starvation period ( 8 days starvation) is probably due to reduced $\mathrm{T}_{4}$ release from the thyroid tissue in juvenile Siberian sturgeon. This adjustment of TH homeostasis during starvation is in broad agreement with previous studies in numerous fish species (Holloway et al. 1994, Van der Geyten et al. 1998, Leiner et al. 2000, De Pedro

\section{- Control $\square$ Starvation}

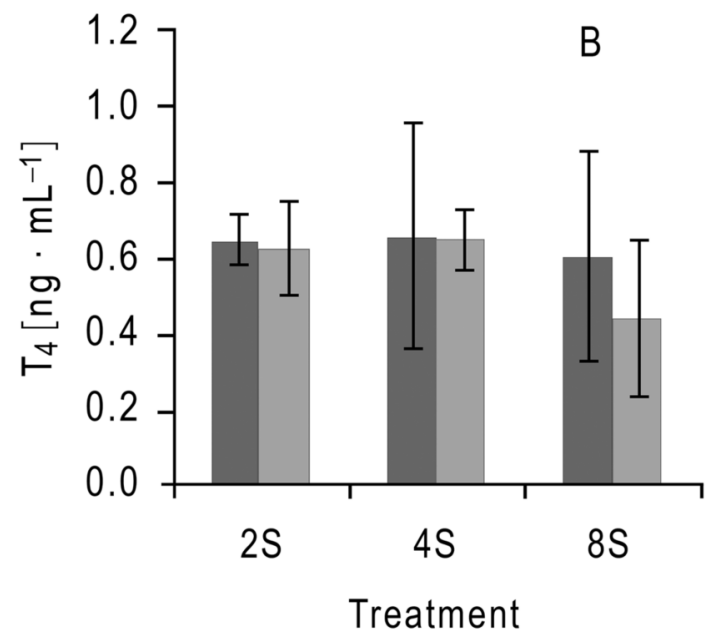

Fig. 1. Levels of plasma thyroid hormones: tri-iodothyronin $\left(\mathrm{T}_{3}\right)(\mathbf{A})$ and thyroxine $\left(\mathrm{T}_{4}\right)(\mathbf{B})$ of juvenile Siberian sturgeon, Acipenser baerii, in starved (black bars) and control (grey bars) groups; Values are mean \pm standard error $(n=9)$; $2 \mathrm{~S}$, $4 \mathrm{~S}$, and $8 \mathrm{~S}$ are starvation groups; No significant differences $(P>0.05)$ between groups at each sampled point 
et al. 2003, Deng et al. 2004, Raine et al. 2005), which has been known as the lowered anabolic capacity of the animal and the mobilization of stored energy reserves. Gaylord et al. (2001) expressed that the reason for the low $\mathrm{TH}\left(\mathrm{T}_{3}\right.$ and $\left.\mathrm{T}_{4}\right)$ concentrations in channel catfish, Ictalurus punctatus (Rafinesque, 1818), during a 3-day starvation period is the diminished sensitivity of the thyroid tissue to thyroid stimulating hormone (TSH).

Basically, proteolysis occurs only when more readily available energy reserves such as liver glycogen and lipid stores in fishes, as in higher vertebrates, have been widely consumed. In the presently reported study, no significant differences were observed in plasma total protein concentrations after short starvation periods, compared with the control group. Farbridge and Leatherland (1992) expressed that there is sequential mobilization of energy reserves in starved rainbow trout, namely first from the liver (carbohydrates and lipids), second from skeletal muscles (carbohydrates and lipids) and then from visceral fat reserves, and extended starves involve loss of body protein. In our study, probably because of the facilitation of fat catabolism in starvation periods, fat reserves were firstly consumed. Moreover, no appreciable alteration observed in plasma protein levels at the first stages of starvation could have occurred as a result of the shortness of starvation periods. In this study, in comparison to $2 \mathrm{~S}$ and $4 \mathrm{~S}$ groups, $8 \mathrm{~S}$ group showed higher plasma total protein levels than those of the two other groups. Furné et al. (2012) observed different effects on plasma total protein levels during starvation period for 72 days in both Adriatic sturgeon, Acipenser naccarii Bonaparte, 1836, and rainbow trout. During starvation, sturgeons are believed to use protein reserves as the third priority after glycogen and fat for obtaining the required energy for metabolism (Hung et al. 1997), which is in agreement with the results acquired in this study. Thus, it is not expected that short-term starvations will greatly change plasma protein levels. Power et al. (2000) found no significant difference in plasma protein levels of gilthead seabream, Sparus aurata Linnaeus, 1758, after a 3-week starvation period, in comparison with the control group. In the short-term starvation of our study, despite not receiving protein from diet, no considerable reduction in plasma protein levels was observed (Ince and Thorpe 1976, Power et al. 2000). In contrast with the results of plasma protein

\section{- Control $\square$ Starvation}

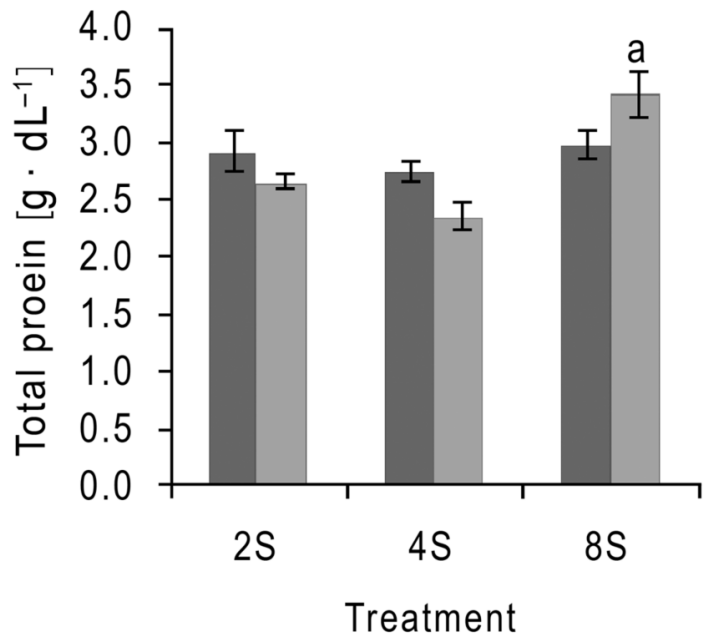

Fig. 2. Plasma total protein levels of juvenile Siberian sturgeon, Acipenser baerii, in starved (black bars) and control (grey bars) groups; Values are mean \pm standard error $(n=9) ; 2 \mathrm{~S}, 4 \mathrm{~S}$, and $8 \mathrm{~S}$ are starvation groups; No significant differences $(P>0.05)$ between the starvation and their control groups, but small letters (columns) indicate statistical differences between the $2 \mathrm{~S}, 4 \mathrm{~S}$, and $8 \mathrm{~S}$ starvation groups $(P<0.05)$

levels in this study, Navarro and Gutiérrez (1995) expressed the opinion that there is a high tendency for plasma protein to decrease in starved fish. Similarly, plasma protein decreased in starved mature carp after five days of starvation (Blasco et al. 1992). Pérez-Jiménez et al. (2012) reported a significant decline in plasma protein levels of common dentex, Dentex dentex (Linnaeus, 1758), after a five-week starvation.

In the presently reported study, the extension of starvation period caused greater consumption of liver reserves and therefore a significant decrease in HSI in $4 \mathrm{~S}$ and $8 \mathrm{~S}$ groups was observed. A similar decrease of this index (HSI) during starvation in fishes was reported in other studies. Ali et al. (2003) observed a significant reduction in HSI in common carp, Cyprinus carpio Linnaeus, 1758, after 8 days of starvation due to consumed liver glycogen. Hung et al. (1997) reported a significant reduction in HSI in white sturgeon, Acipenser

Change in morphometric indices' values in juvenile Siberian sturgeon, Acipenser baerii,

Table 1 after 2, 4, and 8 days of starvation

\begin{tabular}{|c|c|c|c|c|c|c|}
\hline \multirow{2}{*}{ Index $[\%]$} & \multicolumn{2}{|c|}{$8 \mathrm{~S}$} & \multicolumn{2}{|c|}{$4 \mathrm{~S}$} & \multicolumn{2}{|c|}{$2 \mathrm{~S}$} \\
\hline & Starvation & Control & Starvation & Control & Starvation & Control \\
\hline HSI & $1.15 \pm 0.15^{\mathrm{a}}$ & $2.70 \pm 0.52$ & $1.37 \pm 0.18^{\mathrm{a}}$ & $2.36 \pm 0.06$ & $1.71 \pm 0.34$ & $2.26 \pm 0.46$ \\
\hline VSI & $9.79 \pm 0.71^{\mathrm{a}}$ & $15.19 \pm 1.61$ & $9.00 \pm 0.47^{\mathrm{a}}$ & $15.87 \pm 0.39$ & $8.14 \pm 0.99$ & $13.04 \pm 1.68$ \\
\hline DSI & $4.98 \pm 0.22^{\mathrm{a}}$ & $7.29 \pm 0.80$ & $5.05 \pm 0.44^{\mathrm{a}}$ & $11.62 \pm 1.01$ & $4.28 \pm 0.46 \mathrm{a}$ & $9.03 \pm 1.00$ \\
\hline
\end{tabular}

Values are mean \pm standard error $(n=6)$; superscript letter $\left(^{a}\right)$ in the same row indicate significant $(P<0.05)$ differences between the starvation $2(2 \mathrm{~S}), 4(4 \mathrm{~S})$ and $8(8 \mathrm{~S})$ days and their control groups; HSI = hepato-somatic index; VSI = viscerosomatic index; DSI = digestive-somatic index. 
transmontanus Richardson, 1836, after several weeks of starvation. Starvation causes significant decline in both HSI and liver glycogen in European seabass, Dicentrarchus labrax (Linnaeus, 1758) (see Pérez-Jiménez et al. 2007). Montserrat et al. (2007) showed a substantial decrease in HSI in gilthead seabream throughout three weeks of starvation. Consequently, food deprivation can result in a lowered level of HSI, but also VSI and DSI, which shows the key role of the liver- and visceral reserves as energy depots for using in the starvation period. Since Siberian sturgeon prioritize using fat reserves, existing in liver and around intestinal organs, after carbohydrate reserves during starvation, intestinal fat and VSI will decrease (Ince and Thorpe 1976, Love 1980, Hung et al. 1997, Simpkins 2002). In the presently reported study, DSI dramatically decreased in the starvation period, due in part to the evacuation of the digestive tract (defecation) and a reduction in the production of intestinal cells (Furné et al. 2008). Similar findings have been reported in white sturgeon (Hung et al. 1997) and rainbow trout (Storebakken et al. 1998). In European sea bass, VSI decreased by 41 percentage points due to a decrease in visceral lipid depots after 15 days of starvation, compared with the control fish (Gutiérrez et al. 1991). Caruso et al. (2012) similarly observed significant reductions in both HIS and VSI in red porgy, Pagrus pagrus (Linnaeus, 1758), during starvation.

The results of this study indicate that relatively short nutrition stresses such as starvation resulting from transportation, sorting, imposed routine aquaculture procedures, and other factors, have no negative and irreversible effects on Siberian sturgeon. This species has also the ability to adjust its metabolic rate in short-term starvation periods using energy reserves, especially carbohydrates and fats, and to reduce its basal metabolism. Furthermore, the results of this study are indicative of the relation between starvation effects and the extension of the starvation period. It is suggested to assess in future studies, however, the impact of haematological, biochemical, and immunological factors during starvation periods.

\section{ACKNOWLEDGEMENTS}

This study was funded by Khoramshahr Marine Science and Technology University of Iran and with cooperation of Rasht International Sturgeon Research Institute of Iran. The authors are greatly thankful to Dr. Pourkazemi.

\section{REFERENCES}

Ali M., Nicieza A., Wootton R.J. 2003. Compensatory growth in fishes: a response to growth depression. Fish and Fisheries 4 (2): 147-190. DOI: 10.1046/j.1467-2979.2003.00120.x

Bayunova L., Barannikova I., Semenkova T. 2002. Sturgeon stress reactions in aquaculture. Journal of Applied Ichthyology 18 (4-6): 397-404. DOI: 10.1046/j.14390426.2002.00410.x

Bentley P.J. 1998. Hormones and nutrition. Pp. 223-268. In: Bentley P.J. (ed.) Comparative vertebrate endocrinology. 3rd edn. Cambridge University Press, UK.
Blasco J., Fernández J., Gutiérrez. J. 1992. Fasting and refeeding in carp, Cyprinus carpio L.: the mobilization of reserves and plasma metabolite and hormone variations. Journal of Comparative Physiology B 162 (6): 539-546. DOI: $10.1007 / \mathrm{BF} 00264815$

Caruso G., Denaro M.G., Caruso R., Genovese L., Mancari F., Maricchiolo G. 2012. Short fasting and refeeding in red porgy (Pagrus pagrus, Linnaeus 1758): Response of some haematological, biochemical and non specific immune parameters. Marine Environmental Research 81: 18-25. DOI: 10.1016/j.marenvres.2012.07.003

Cataldi E., Di Marco P., Mandich A., Cataudella S. 1998. Serum parameters of Adriatic sturgeon Acipenser naccarii (Pisces: Acipenseriformes): effects of temperature and stress. Comparative Biochemistry and Physiology, Part A: Molecular and Integrative Physiology 121 (4): 351-354. DOI: 10.1016/s1095-6433(98)10134-4

De Pedro N., Delgado M.J., Gancedo B., Alonso-Bedate M. 2003. Changes in glucose, glycogen, thyroid activity and hypothalamic catecholamines in tench by starvation and refeeding. Journal of Comparative Physiology173 (6): 475-481. DOI: 10.1007/s00360-003-0355-7

Deng L., Zhang W.M., Lin H.R., Cheng C.H.K. 2004. Effects of food deprivation on expression of growth hormone receptor and proximate composition in liver of black seabream Acanthopagrus schlegeli. Comparative Biochemistry and Physiology, Part B: Biochemistry and Molecular Biology 137 (4): 421-432. DOI: 10.1016/j.cbpc.2004.01.008

Duncan D.B. 1955. Multiple range and multiple $F$ tests. Biometrics 11 (1): 1-42.

Farbridge K.J., Leatherland J.F. 1992. Temporal changes in plasma thyroid hormone, growth hormone and free fatty acid concentrations, and hepatic 5'-monodeiodinase activity, lipid and protein content during chronic fasting and refeeding in rainbow trout (Oncorhynchus mykiss). Fish Physiology and Biochemistry 10 (3): 245-257. DOI: 10.1007/BF00004518

Fontagné S., Bazin D., Brèque J., Vachot Ch., Bernarde C., Rouault Th., Bergot P. 2006. Effects of dietary oxidized lipid and vitamin A on the early development and antioxidant status of Siberian sturgeon (Acipenser baeri) larvae. Aquaculture 257 (1-4): 400-411. DOI: 10.1016/ j.aquaculture.2006.01.025

Fuglei E., Aanestad M., Berg J.P. 2000. Hormones and metabolites of arctic foxes (Alopex lagopus) in response to season, starvation and re-feeding. Comparative Biochemistry and Physiology, Part A: Molecular and Integrative Physiology 126 (2): 287-294. DOI: 10.1016/s1095-6433(00)00211-7

Furné M., García-Gallego M., Hidalgo M.C., Morales A.E., Domezain A., Domezain J., Sanz A. 2008. Effect of starvation and refeeding on digestive enzyme activities in sturgeon (Acipenser naccarii) and trout (Oncorhynchus mykiss). Comparative Biochemistry and Physiology, Part A: Molecular and Integrative Physiology 149 (4): 420-425. DOI: 10.1016/j.cbpa.2008.02.002

Furné M., Morales A.E., Trenzado C.E., García-Gallego M., Hidalgo M.C., Domezain A., Sanz Rus A. 2012. The meta- 
bolic effects of prolonged starvation and refeeding in sturgeon and rainbow trout. Journal of Comparative Physiology B 182 (1): 63-76. DOI: 10.1007/s00360-011-0596-9

Gaylord T.G., MacKenzie D.S., Gatlin D.M.III 2001. Growth performance, body composition and plasma thyroid hormone status of channel catfish (Ictalurus punctatus) in response to short-term feed deprivation and refeeding. Fish Physiology and Biochemistry 24 (1): 73-79. DOI: 10.1023/A:1011199518135

Gutiérrez J., Pérez J., Navarro I., Zanuy S., Carrillo M. 1991. Changes in plasma glucagon and insulin associated with fasting in sea bass (Dicentrarchus labrax). Fish Physiology and Biochemistry 9 (2): 107-112. DOI: 10.1007/BF02265126

Holloway A.C., Reddy P.K., Sheridan M.A., Leatherland J.F. 1994. Diurnal rhythms of plasma growth hormone, somatostatin, thyroid hormones, cortisol and glucose concentrations in rainbow trout, Oncorhynchus mykiss, during progressive food deprivation. Biological Rhythm Research 25 (4): 415-432. DOI: 10.1080/09291019409360312

Honma Y., Matsui I. 1973. [Histological observations on a specimen of the Japanese eel, Anguiila japonica, under the long-term starvation.] Journal of Shimonoseki University of Fisheries 21 (3): 285-293. [In Japanese.]

Hornick J.L., Van Eenaeme C., Gérard O., Dufrasne I., Istasse L. 2000. Mechanisms of reduced and compensatory growth. Domestic Animal Endocrinology 19 (2): 121-132. DOI: $10.1016 / \mathrm{S} 0739-7240(00) 00072-2$

Hung S.S.O., Liu W., Li H., Storebakken T., Cui Y. 1997. Effect of starvation on some morphological and biochemical parameters in white sturgeon, Acipenser transmontanus. Aquaculture 151 (1-4): 357-363. DOI: 10.1016/S00448486(96)01506-2

Ince B.W., Thorpe A. 1976. The effects of starvation and forcefeeding on the metabolism of the northern pike, Esox lucius L. Journal of Fish Biology 8 (1): 79-88. DOI: 10.1111/j.10958649.1976.tb03909.x

Leatherland J.F., Farbridge K.J. 1992. Chronic fasting reduces the responses of the thyroid to growth hormone and $\mathrm{TSH}$, and alters the growth hormone-related changes in hepatic 5'-monodeiodinase activity in rainbow trout, Oncorhynchus mykiss. General and Comparative Endocrinology 87 (3): 342-353. DOI: 10.1016/00166480(92)90040-Q

Leiner K.A., Han G.S., MacKenzie D.S. 2000. The effects of photoperiod and feeding on the diurnal rhythm of circulating thyroid hormones in the red drum, Sciaenops ocellatus. General and Comparative Endocrinology 120 (1): 88-98. DOI: $10.1006 /$ gcen.2000.7539

Love R.M. 1980. Feeding and starvation. Pp. 133-229. In: The chemical biology of fishes, Vol. 2: Advances 1968-1977. Academic Press, London and New York.

MacKenzie D.S., VanPutte C.M., Leiner K.A. 1998. Nutrient regulation of endocrine function in fish. Aquaculture $161(1-4)$ : 3-25. DOI: 10.1016/S0044-8486(97)00253-6

McBride J.R. 1967. Effects of feeding on the thyroid, kidney, and pancreas in sexually ripening adult sockeye salmon
(Oncorhynchus nerka). Journal of the Fisheries Research Board of Canada 24 (1): 67-76. DOI: 10.1139/f67-007

Montserrat N., Gómez-Requeni P., Bellini G., Capilla E., Pérez-Sánchez J., Navarro I., Gutiérrez J. 2007. Distinct role of insulin and IGF-I and its receptors in white skeletal muscle during the compensatory growth of gilthead sea bream (Sparus aurata). Aquaculture 267 (1-4): 188-198. DOI: 10.1016/j.aquqculture.2007.04.024

Navarro I., Gutiérrez J. 1995. Fasting and starvation. Pp. 393-434. In: Hochachka P.W., Mommsen T. (eds.) Biochemistry and molecular biology of fishes. Vol. 4. Elsevier, New York, NY, USA.

Pérez-Jiménez A., Cardenete G., Hidalgo M.C., GarcíaAlcázar A., Abellán E., Morales A.E. 2012. Metabolic adjustments of Dentex dentex to prolonged starvation and refeeding. Fish Physiology and Biochemistry 38 (4): 1145-1157. DOI: 10.1007/s10695-011-9600-2

Pérez-Jiménez A., Guedes M.J., Morales A.E., Oliva-Teles A. 2007. Metabolic responses to short starvation and refeeding in Dicentrarchus labrax. Effect of dietary composition. Aquaculture 265 (1-4): 325-335. DOI: 10.1016/ j.aquaculture.2007.01.021

Pottinger T.G., Rand-Weaver M., Sumpter J.P. 2003. Overwinter fasting and re-feeding in rainbow trout: plasma growth hormone and cortisol levels in relation to energy mobilisation. Comparative Biochemistry and Physiology, Part B: Biochemistry and Molecular Biology 136 (3): 403-417. DOI: 10.1016/S1096-4959(03)00212-4

Power D.M., Melo J., Santos C.R.A. 2000. The effect of food deprivation and refeeding on the liver, thyroid hormones and transthyretin in sea bream. Journal of Fish Biology 56 (2): 374-387. DOI: 10.1006/jfbi.1999.1165

Raine J.C., Cameron C., Vijayan M.M., MacKenzie D.S., Leatherland J.F. 2005. Effect of fasting on thyroid hormone levels, and TR $\alpha$ and TR $\beta$ mRNA accumulation in latestage embryo and juvenile rainbow trout, Oncorhynchus mykiss. Comparative Biochemistry and Physiology, Part A: Molecular and Integrative Physiology 140 (4): 452-459. DOI: $10.1016 /$ j.cbpb.2005.02.007

Storebakken T., Shearer K.D., Refstie S., Lagocki S., McCool J. 1998. Interactions between salinity, dietary carbohydrate source and carbohydrate concentration on the digestibility of macronutrients and energy in rainbow trout (Oncorhynchus mykiss). Aquaculture 163 (3-4): 347-359. DOI: 10.1016/S0044-8486(98)00259-2

Van der Geyten S., Mol K.A., Pluymers W., Kühn E.R., Darras V.M. 1998. Changes in plasma $\mathrm{T}_{3}$ during fasting/refeeding in tilapia (Oreochromis niloticus) are mainly regulated through changes in hepatic type II iodothyronine deiodinase. Fish Physiology and Biochemistry 19 (2): 135-143. DOI: 10.1023/A:1007790527748

Received: 1 January 2013 Accepted: 1 June 2013 Published electronically: 30 June 2013 